\title{
Oxidative Stress, Mitochondrial Dysfunction, and Aging
}

\author{
Hang Cui, Yahui Kong, and Hong Zhang \\ Department of Cell Biology, University of Massachusetts Medical School, Worcester, MA 01655, USA \\ Correspondence should be addressed to Hong Zhang, hong.zhang@umassmed.edu
}

Received 15 May 2011; Accepted 3 August 2011

Academic Editor: Paolo Pinton

Copyright ( $) 2012$ Hang Cui et al. This is an open access article distributed under the Creative Commons Attribution License, which permits unrestricted use, distribution, and reproduction in any medium, provided the original work is properly cited.

\begin{abstract}
Aging is an intricate phenomenon characterized by progressive decline in physiological functions and increase in mortality that is often accompanied by many pathological diseases. Although aging is almost universally conserved among all organisms, the underlying molecular mechanisms of aging remain largely elusive. Many theories of aging have been proposed, including the freeradical and mitochondrial theories of aging. Both theories speculate that cumulative damage to mitochondria and mitochondrial DNA (mtDNA) caused by reactive oxygen species (ROS) is one of the causes of aging. Oxidative damage affects replication and transcription of mtDNA and results in a decline in mitochondrial function which in turn leads to enhanced ROS production and further damage to mtDNA. In this paper, we will present the current understanding of the interplay between ROS and mitochondria and will discuss their potential impact on aging and age-related diseases.
\end{abstract}

\section{Introduction}

The fundamental manifestation of the aging process is a progressive decline in the functional maintenance of tissue homeostasis and an increasing propensity to degenerative diseases and death [1]. It has attracted significant interest to study the underlying mechanisms of aging, and many theories have been put forward to explain the phenomenon of aging. There is an emerging consensus that aging is a multifactorial process, which is genetically determined and influenced epigenetically by environment [2]. Most aging theories postulate a single physiological cause of aging, and likely these theories are correct to a certain degree and in certain aspects of aging.

Reactive oxygen species (ROS) are highly reactive molecules that consist of a number of diverse chemical species including superoxide anion $\left(\mathrm{O}_{2}{ }^{-}\right)$, hydroxyl radical $(\cdot \mathrm{OH})$, and hydrogen peroxide $\left(\mathrm{H}_{2} \mathrm{O}_{2}\right)$. Because of their potential to cause oxidative deterioration of DNA, protein, and lipid, ROS have been implicated as one of the causative factors of aging [3]. As ROS are generated mainly as byproducts of mitochondrial respiration, mitochondria are thought to be the primary target of oxidative damage and play an important role in aging. Emerging evidence has linked mitochondrial dysfunction to a variety of age-related diseases, including neurodegenerative diseases and cancer. Details of the precise relationship between ROS-induced damage, mitochondrial dysfunction, and aging remain to be elucidated.

\section{ROS and Aging}

2.1. ROS, Oxidative Damage, and Cellular Signaling. There are several sources of ROS within a cell. ROS are generated as by-products of aerobic respiration and various other catabolic and anabolic processes [4]. Mitochondria are the major producer of ROS in cells, and the bulk of mitochondrial ROS is generated at the electron transport chain $[5,6]$. Electrons leak from the electron transport chain directly to oxygen, producing short-lived free radicals such as superoxide anion $\left(\mathrm{O}_{2}{ }^{-}\right)[7,8] . \mathrm{O}_{2}{ }^{-}$can be converted to nonradical derivatives such as hydrogen peroxide $\left(\mathrm{H}_{2} \mathrm{O}_{2}\right)$ either spontaneously or catalyzed by superoxide dismutase (SOD) [9-13]. $\mathrm{H}_{2} \mathrm{O}_{2}$ is relatively stable and membrane permeable. It can be diffused within the cell and be removed by cytosolic antioxidant systems such as catalase, glutathione peroxidase, and thioredoxin peroxidase $[14,15]$. In addition to being generated during cellular metabolism in mitochondria, ROS can be produced in response to different environmental stimuli such as growth factors, inflammatory cytokines, ionizing radiation, UV, chemical oxidants, chemotherapeutics, 
hyperoxia, toxins, and transition metals [16-26]. Other than mitochondrial respiration, a number of cytosolic enzymes are able to generate ROS [27]. The nicotinamide adenine dinucleotide phosphate (NADPH) oxidases are a group of plasma membrane-associated enzymes found in a variety of cell types [28]. The function of NADPH oxidases is to produce superoxide from oxygen using electrons from NADPH [29].

Once they are produced, ROS react with lipids, proteins, and nucleic acids causing oxidative damage to these macromolecules [30-34]. ROS readily attack DNA and generate a variety of DNA lesions, such as oxidized DNA bases, abasic sites, and DNA strand breaks, which ultimately lead to genomic instability [35]. 7,8-dihydro-8-oxodeoxyguanosine (8-oxo-dG) is one of the most abundant and well-characterized DNA lesions caused by ROS [36]. It is a highly mutagenic lesion that results in $\mathrm{G}: \mathrm{C}$ to $\mathrm{T}: \mathrm{A}$ transversions [37]. To limit the cellular damage caused by ROS, mammalian cells have evolved a number of sophisticated defense mechanisms. ROS-generated DNA lesions are repaired mainly by base excision repair as well as other DNA repair pathways including nucleotide excision repair, double-strand break repair, and mismatch repair [38-40]. In addition, the damaging effects of ROS can be neutralized via elevated antioxidant defense, which includes superoxide dismutase, catalase, and glutathione peroxidase to scavenge ROS to nontoxic forms [41].

Intracellular ROS are normally maintained at low but measurable level within a narrow range, which is regulated by the balance between the rate of production and the rate of scavenging by various antioxidants [42]. ROS, at low level under normal conditions, is found to act as signaling molecules in many physiological processes, including redox homeostasis and cellular signal transduction [7]. By activating proteins such as tyrosine kinases, mitogenactivated protein kinases, or Ras proteins, ROS are important mediators of signal transduction pathways [7]. Dependent on cell types, ROS have been found to function as signaling molecules in cell proliferation [43], cellular senescence [44], or cell death $[45,46]$. The divergent effects of ROS on many cellular processes suggest that ROS are not merely detrimental byproducts, but also generated purposefully to mediate a variety of signaling pathways.

2.2. The Free Radical Theory of Aging. The free radical theory of aging proposed by Denham Harman more than fifty years ago postulates that aging results from the accumulation of deleterious effects caused by free radicals, and the ability of an organism to cope with cellular damage induced by ROS plays an important role in determining organismal lifespan [3]. In agreement with this theory, increased ROS production by mitochondria and increased 8-oxo-dG content in the mtDNA are frequently detected in aged tissues [40, 47-50], suggesting that progressive accumulation of oxidative DNA damage is a contributory factor to the aging process. Consistently, many studies have found that increased oxidative damage in cells is associated with aging [51-53]. Furthermore, genetic studies in worm, fly, and mouse have linked enhanced stress resistance or reduced free radical production with increased lifespan [27]. Mutant strains of C. elegans that are resistant to oxidative stress have extended lifespan, whereas those more susceptible to free radicals have shortened lifespan $[54,55]$. Mice lacking the antioxidant enzyme superoxide dismutase 1 (SOD1) exhibit a 30\% decrease in life expectancy [56]. Conversely, simultaneous overexpression of SOD1 and catalase extends lifespan in Drosophila [57]. Small synthetic mimetics of SOD/catalase increase lifespan in C. elegans [58], while treatment of antioxidant drugs in mice increases the median lifespan up to $25 \%[59,60]$. Further supporting this hypothesis, mice lacking Ogg1 and Myh, two enzymes of the base excision repair pathway that repairs oxidative DNA damage, show a 50\% reduction in life expectancy [61]. Collectively, these studies demonstrate that interplay between ROS and protective antioxidant responses is an important factor in determining aging and lifespan.

Despite a large body of evidence supporting the role of ROS in aging, the free radical theory of aging faces some challenges [62]. Mice heterozygous for superoxide dismutase $2\left(\mathrm{Sod}_{2}{ }^{+-}\right)$have reduced manganese SOD (MnSOD) activity, increased oxidative damage, but normal lifespan [63]. Overexpression of antioxidant enzymes in mice, such as SOD1 or catalase, does not extend lifespan [64, 65]. The median lifespan of mice heterozygous of glutathione peroxidase $4\left(\mathrm{Gpx}^{+/-}\right)$, an antioxidant defense enzyme that plays an important role in detoxification of oxidative damage to membrane lipids, is significantly longer than that of wild-type mice, even though $\mathrm{Gpx}^{+/-}$mice show increased sensitivity to oxidative stress-induced apoptosis [66]. Studies of long-lived rodents also do not find a convincing correlation between level of oxidative damage and aging [67]. Furthermore, pharmacologic intervention with antioxidants in humans and mice has little effect on prolonging lifespan [68-70]. More investigations are clearly needed to clarify the discrepancy in the role of ROS and antioxidant enzymes in aging among different species and to understand the precise role that free radicals play in aging.

2.3. ROS and Senescence. Senescence, a process in which normal somatic cells enter an irreversible growth arrest after a finite number of cell divisions [71], is thought to contribute to organismal aging [72-74]. Senescent cells are associated with high level of intracellular ROS and accumulated oxidative damage to DNA and protein [7577]. In contrast, immortal cells suffer less oxidative damage and are more resistant to the deleterious effects of $\mathrm{H}_{2} \mathrm{O}_{2}$ than primary cells [78]. Increasing intracellular oxidants by altering ambient oxygen concentrations or lowering antioxidant levels accelerates the onset of senescence, while lowering ambient oxygen or increasing ROS scavenging delays senescence [76, 78-81].

Telomere shortening is considered as the major cause of replicative senescence $[82,83]$. It has been reported that the rate of telomere shortening is directly related to the cellular level of oxidative stress [84]. Telomere shortening is significantly increased under mild oxidative stress as compared to 
that observed under normal conditions, whereas overexpression of the extracellular SOD in human fibroblasts decreases the peroxide content and the rate of telomere shortening [79]. ROS can affect telomere maintenance at multiple levels. The presence of 8-oxoguanine (8-oxoG), an oxidative derivative of guanine, in telomeric repeat-containing DNA oligonucleotides has been shown to impair the formation of intramolecular $\mathrm{G}$ quadruplexes and reduces the affinity of telomeric DNA for telomerase, thereby interfering with telomerase-mediated extension of single-stranded telomeric DNA [85]. ROS also affect telomeres indirectly through their interaction with the catalytic subunit of telomerase, telomerase reverse transcriptase (TERT). Increased intracellular ROS lead to loss of TERT activity, whereas ROS scavengers such as $\mathrm{N}$-acetylcysteine (NAC) block ROSmediated reduction of TERT activity and delay the onset of cellular senescence [86]. Furthermore, the presence of 8oxoG in the telomeric sequence reduces the binding affinity of TRF1 and TRF2 to telomeres [87]. TRF1 and TRF2 are components of the telomere-capping shelterin complex that protects the integrity of telomeres [88]. In addition, ROS-induced DNA damage elicits a DNA damage response, leading to the activation of p53 [89], a critical regulator of senescence. It has been shown that p53 transactivates E3 ubiquitin ligase Siah1, which in turn mediates ubiquitination and degradation of TRF2. Consequently, knockdown of Siah1 expression stabilizes TRF2 and delays the onset of replicative senescence [90]. The p53-Siah1-TRF2 regulatory axis places p53 both downstream and upstream of DNA damage signaling initiated by telomere dysfunction. By regulating telomere maintenance or integrity directly or indirectly, ROS plays a critical role in senescence.

2.4. ROS and Stem Cell Aging. Tissue-specific or adult stem cells, which are capable of self-renewal and differentiation, are essential for the normal homeostatic maintenance and regenerative repair of tissues throughout the lifetime of an organism. The self-renewal ability of stem cells is known to decline with advancing age [91-94], suggesting that decline in stem cell function plays a central role in aging. Increasing evidence suggests that dysregulated formation of ROS may drive stem and progenitor cells into premature senescence and therefore impede normal tissue homeostasis.

Genetic studies of mice deficient in genes implicated in ROS regulation indicate that elevated level of ROS within the stem cell compartments leads to a rapid decline in stem cell self-renewal [95-98]. Deletion of Ataxia telangiectasia mutated (ATM) kinase results in increased ROS level in hematopoietic stem cell (HSC) population in aged mice, which correlates with a rapid decline in HSC number and function [95]. When $\mathrm{Atm}^{-/-}$mice are treated with antioxidants, the defect in stem cell self-renewal is rescued [95], suggesting that high level of ROS causes the decline in stem cell function. Furthermore, deficiency in telomerase reverse transcriptase (TERT) accelerates the progression of aging, resulting in an even shorter lifespan in $\mathrm{Atm}^{-/-}$ mice accompanied by increased senescence in hematopoietic tissues and decreased stem cell activity [99]. These TERTdeficient HSCs are also sensitive to ROS-induced apoptosis, suggesting another possible cause of stem cell impairment during aging [99]. Similarly, defect in HSC number and activity accompanied by increased accumulation of ROS is observed in mice lacking three members of Forkhead box O-class (FoxO) [96-98]. Increased level of ROS in FoxO3-null myeloid progenitors leads to hyperproliferation through activation of the AKT/mTOR signaling pathway, and ultimately premature exhaustion of progenitors [100]. Mice carrying a mutation in inner mitochondrial membrane peptidase 2-like (Immp2l) gene, which is required to process signal peptide of mitochondrial cytochrome $\mathrm{cl}$ and glycerol phosphate dehydrogenase 2, exhibit an early onset of aging phenotypes, including premature loss of fat [101]. Elevated mitochondrial ROS level in the Immp2l mutant mice leads to impaired self-renewal of adipose progenitor cells, suggesting that ROS-induced damage to adult stem cells is the driving force of accelerated aging in these mice [101]. Further supporting this notion, intracellular level of ROS is found to correlate with the long-term self-renewal ability of HSCs in mouse [102]. HSCs with high level of ROS show a decreased ability of long-term self-renewal, and treatment of antioxidant NAC is able to restore the functional activity of HSCs with high level of ROS [102]. Taken together, these studies suggest that ROS play an important role in stem cell aging.

ROS-generated DNA lesions are repaired by several DNA repair pathways including base excision repair, nucleotide excision repair, double-strand break repair, and mismatch repair [38-40]. Endogenous DNA damage accumulates with age in HSCs in mouse. HSCs in mice deficient in DNA repair pathways, including nucleotide excision repair, telomere maintenance, and nonhomologous end-joining, exhibit increased sensitivity to the detrimental effect of ROS, diminished self-renewal and functional exhaustion with age [103]. These data support the notion that accumulated DNA damage is one of the principal mechanisms underlying agedependent stem cell decline.

\section{Mitochondria and Aging}

3.1. The Mitochondrial Theory of Aging. Because mitochondria are the major producer of ROS in mammalian cells, the close proximity to ROS places mitochondrial DNA (mtDNA) prone to oxidative damage [104]. Consistently, many studies have shown that 8-oxo-dG, one of the common oxidative lesions, is detected at higher level in mtDNA than nuclear DNA, suggesting that mtDNA is more susceptible to oxidative damage [52, 105-113]. As both the major producer and primary target of ROS, mitochondria are thought to play an important role in aging. The mitochondrial theory of aging, extended from the free radical theory, proposes that oxidative damage generated during oxidative phosphorylation of mitochondrial macromolecules such as mtDNA, proteins, or lipids is responsible for aging [114]. As mtDNA encodes essential components of oxidative phosphorylation 
and protein synthesis machinery [115], oxidative damageinduced mtDNA mutations that impair either the assembly or the function of the respiratory chain will in turn trigger further accumulation of ROS, which results in a vicious cycle leading to energy depletion in the cell and ultimately cell death $[104,114,116-118]$.

As mitochondria play a critical role in regulation of apoptosis, which is implicated in the aging process [119], age-related mitochondrial oxidative stress may contribute to apoptosis upon aging. The activation of the permeability transition pore in mitochondria, which is believed to play a critical role in cell necrosis and apoptosis, is enhanced in spleen, brain, and liver of aged mice [120, 121]. Moreover, mitochondrial adenine nucleotide translocase, a component of the permeability transition pore, exhibits an age-associated increase of oxidative modification in male houseflies [122]. Such selective oxidative modification may cause the cells more vulnerable to apoptotic inducers [123]. Thus, mitochondria appear to influence the aging process via modifying the regulatory machinery of apoptosis.

Mice expressing proof reading-deficient mitochondrial DNA polymerase show a consistent increase in mtDNA mutations, premature onset of the aging phenotypes and reduced lifespan $[124,125]$, suggesting a critical link between mitochondria and aging. Interestingly, ROS production in these mice is not increased $[124,125]$. Similarly, mice expressing proof reading-deficient mitochondrial DNA polymerase specifically in heart show accumulation of mutations in mtDNA and develop cardiomyopathy, but oxidative stress in the transgenic heart is not increased, indicating that oxidative stress is not an obligate mediator of diseases provoked by mtDNA mutations [126]. More studies are required to further clarify the consequence of oxidative stress and mitochondrial dysfunction in aging.

3.2. Age-Associated Changes of Mitochondria. Mitochondrial genome encodes proteins required for oxidative phosphorylation and ATP synthesis, and RNAs needed for mitochondrial protein translation [115]. The mtDNA is densely packed with genes and only contains one noncoding region called the displacement loop (D-loop) [127]. The D-loop is important for mtDNA replication and transcription and has been extensively studied for the presence of age-related mutations [115]. Age-dependent accumulation of point mutations within the D-loop has been reported in various types of cells and tissues, including skin and muscle [128132]. In addition to point mutations, deletions of mtDNA are detected at higher frequency in aged human and animal tissues [133-145]. Replication is thought to be the likely mechanism leading to the formation of mtDNA deletions [146-148], but recent studies suggest that mtDNA deletions may be generated during repair of damaged mtDNA rather than during replication [149]. It is thought that repair of oxidative damage to mtDNA accumulated during aging leads to generation of double-strand breaks [149], with single-strand regions free to anneal with microhomologous sequences on other single-stranded mtDNA or within the noncoding region [150]. Subsequent repair, ligation and degradation of the remaining exposed single strands would result in the formation of an intact mitochondrial genome harboring a deletion [149]. Whether and how exactly mutations and deletions of mtDNA cause the aging phenotypes are not clear. Among mtDNA deletions during aging, especially in postmitotic tissues like muscle and brain, the most common one is a 4977-bp deletion [151-153]. The frequency of this deletion increases in brain, heart, and skeletal muscle with age, although the increase varies in different tissues of the same individual [154], or even in different regions of the same tissue $[134,136,137]$. This deletion occurs in a region encoding subunits of the NADH dehydrogenase, cytochrome $c$ oxidase, and ATP synthase [155]. Whether deletion of these genes plays a causative role in the development of aging phenotypes remains to be determined.

In addition to age-associated increase of mtDNA mutations and deletions, the abundance of mtDNA also declines with age in various tissues of human and rodent [156158]. For instance, in a large group of healthy men and women aged from 18 to 89 years, mtDNA and mRNA abundance is found to decline with advancing age in the vastus lateralis muscle. Furthermore, abundance of mtDNA correlates with the rate of mitochondrial ATP production [158], suggesting that age-related mitochondrial dysfunction in muscle is related to reduced mtDNA abundance. However, age-associated change in mtDNA abundance seems to be tissue specific, as several studies have reported no change in mtDNA abundance with age in other tissues in human and mouse [159-161]. It is possible that tissue-specific effect of aging on mtDNA abundance is related to the status of aerobic activity $[156,158]$, as aerobic exercise has been shown to enhance muscle mtDNA abundance in both human and mouse [162-164]. Increased prevalence of mtDNA mutations/deletions and decreased mtDNA abundance offer attractive underlying causes of mitochondrial dysfunction in aging, which warrants further investigation.

\subsection{Mitochondria Malfunction in Age-Associated Human} Diseases. A heterogeneous class of disorders with a broad spectrum of complex clinical phenotypes has been linked to mitochondrial defect and oxidative stress $[165,166]$. Particularly, mitochondria are thought to play an important role in the pathogenesis of age-associated neurodegenerative diseases, such as Alzheimer's disease, Parkinson's disease, and Huntington's disease. This is not surprising as neurons are especially sensitive and vulnerable to any abnormality in mitochondrial function because of their high energy demand.

Alzheimer's disease (AD) is the most common form of dementia and often diagnosed in people over 65 years of age. $\mathrm{AD}$ is characterized by severe neurodegenerative changes, such as cerebral atrophy, loss of neurons and synapses, and selective depletion of neurotransmitter systems in cerebral cortex and certain subcortical region [167]. Mitochondria are significantly reduced in various types of cells obtained from patients with $\mathrm{AD}$ [168-170]. Dysfunction of mitochondrial electron transport chain has also been associated with 
the pathophysiology of $\mathrm{AD}$ [170]. The most consistent defect in mitochondrial electron transport enzymes in $\mathrm{AD}$ is a deficiency in cytochrome $c$ oxidase $[171,172]$, which leads to an increase in ROS production, a reduction in energy stores, and disturbance in energy metabolism [173].

Parkinson's disease (PD) is the second most common progressive disorder of the central nervous system, which is characterized prominently by loss of dopaminergic neurons in the substantia nigra and formation of intraneuronal protein aggregates [174]. The finding that exposure to environmental toxins, which inhibit mitochondrial respiration and increase production of ROS, causes loss of dopaminergic neurons in human and animal models leads to a hypothesis that oxidative stress and mitochondrial dysfunction are involved in PD pathogenesis [175]. Consistent with this notion, a significant decrease in the activity of complex I of the electron transport chain is observed in the substantia nigra from PD patients [176]. Furthermore, neurotoxin 1methyl-4-phenyl-1,2,3,6-tetrahydropyridine, which acts as an inhibitor of complex I, can induce parkinsonism in human, monkey, and rodent [177, 178]. Genetic studies of PINK1 and PARKIN further support the role of mitochondrial dysfunction in pathogenesis of $\operatorname{PD}[179,180]$. Autosomal recessive mutations in PINK1 and PARKIN are associated with juvenile Parkinsonism [181-183]. Studies in Drosophila have provided strong evidence that PINK1 and PARKIN act in the same genetic pathway to control mitochondrial morphology in tissues with high energy demand and requirement of proper mitochondrial function, such as indirect flight muscle and dopaminergic neurons [184-186]. Consistent with the finding in Drosophila, primary fibroblasts derived from patients with PINK1 mutations show similar abnormalities in mitochondrial morphology [187]. The morphologic changes of mitochondria can be rescued by expression of wild-type PARKIN but not pathogenic PARKIN mutants [187], suggesting that mitochondrial dynamics plays an important role in PD pathogenesis.

Huntington's disease (HD) is another hereditary neurodegenerative disorder that affects muscle coordination and leads to cognitive decline and dementia. HD is caused by an autosomal dominant mutation in the Huntingtin (HTT) gene [188]. Morphologic defects of mitochondria, such as reduced mitochondrial movement and alterations in mitochondrial ultrastructures, have been observed in patients with HD or transgenic HD mouse models [189, 190]. In addition, expression of mutant HTT leads to impaired energy metabolism, abnormal $\mathrm{Ca}^{2+}$ signaling and mitochondrial membrane potential, and drastic changes in mitochondrial ultrastructures [191, 192]. Although the underlying molecular mechanism remains to be determined, it is recently proposed that mutant HTT conveys its neurotoxicity by evoking defects in mitochondrial dynamics, mitochondrial fission and fusion, and organelle trafficking, which in turn result in bioenergetic failure and HDassociated neuronal dysfunction [189].

Mitochondrial dysfunction and increased oxidative damage are often associated with $\mathrm{AD}, \mathrm{PD}$, and $\mathrm{HD}$, suggesting that oxidative stress may play an important role in the pathophysiology of these diseases [193]. Increased production of cellular ROS and oxidative stress have been reported to induce autophagy, a homeostatic process that enables cells to degrade cytoplasmic proteins and organelles [194197]. The observation of increased autophagy in the brains of patients with $\mathrm{AD}, \mathrm{PD}$, and $\mathrm{HD}$ suggests that autophagy contributes to the pathogenesis of these neurodegenerative diseases, possibly by causing cell death [170, 198-202]. Consistently, oxidative stress-induced autophagy of accumulated amyloid $\beta$-protein in $\mathrm{AD}$ causes permeabilization of lysosomal membrane and leads to neuronal cell death [203]. Mitochondria damaged by significantly increased oxidative stress in pyramidal neurons of $\mathrm{AD}$ are subjected to autophagic degradation, ultimately leading to neurodegeneration [204]. Furthermore, overexpression of wildtype PINK1 increases mitochondrial interconnectivity and suppresses toxin-induced autophagy, whereas knockdown of PINK1 expression potentiates mitochondrial fragmentation and induces autophagy [197], suggesting that induced autophagy as a consequence of loss of function of PINK1 may contribute to the pathogenesis of PD.

Interestingly, autophagy also serves as a protective mechanism in age-related neurodegenerative diseases. Several studies demonstrate that basal level of autophagy clears the deleterious protein aggregates that are associated with $\mathrm{AD}$, $\mathrm{PD}$, and HD [205-207], therefore playing a protective role in the maintenance of neural cells. For instance, autophagy is involved in degradation of HTT aggregates [198]. Administration of rapamycin induces autophagy and enhances the clearance of mutant HTT, improving cell viability and ameliorating HD phenotypes in cell and animal models [208]. Furthermore, PARKIN, whose loss of function mutation causes early onset PD, has been found to promote autophagy of depolarized mitochondria [209], suggesting that a failure to eliminate damaged mitochondria by mutant PARKIN is responsible for the pathogenesis of PD. It is not entirely clear why autophagy can exert protective or deleterious effects on pathogenesis of these neurodegenerative diseases. A better understanding of autophagy, mitochondrial dysfunction, and oxidative stress is necessary in order to dissect the pathogenesis of $\mathrm{AD}, \mathrm{PD}$, and $\mathrm{HD}$.

Cancer is considered an age-associated disease, as the incidence of cancer increases exponentially with age. Warburg first discovered that cancer cells constitutively metabolize glucose and produce excessive lactic acid even in the presence of abundant oxygen, a phenomenon named "aerobic glycolysis" [210]. In contrast, normal cells generate energy mainly from oxidative breakdown of pyruvate, which is an end product of glycolysis and is oxidized in mitochondria. Conversion of glucose to lactate only takes place in the absence of oxygen (termed "Pasteur effect") in normal cells. He hypothesized that defect in mitochondrial respiration in tumor cells is the cause of cancer, and cancer should be interpreted as mitochondrial dysfunction [210]. A growing body of evidence has demonstrated the presence of both somatic and germline mutations in mtDNA in various types of human cancers [211-213]. The most direct evidence that mtDNA mutations may play an important role in neoplastic transformation comes from the study by introducing 
a known pathogenic mtDNA mutation T8993G into the prostate cancer cell line PC3 through transmitochondrial cybrids [214]. The T8993G mutation derived from a mitochondrial disease patient causes a $70 \%$ reduction in ATP synthase activity and a significant increase in mitochondrial ROS production [215]. Tumor growth in the T8993G mutant cybrids is much faster than that in the wild-type control cybrids [214]. Moreover, staining of tumor sections confirms a dramatic increase in ROS production in T8993G mutant tumors, suggesting that mitochondrial dysfunction and ROS elevation contribute to tumor progression. Consistent with this notion, the Sod2 $2^{+/-}$mice exhibit increased oxidative damage and enhanced susceptibility to cancer as compared to wild-type mice [63]. Collectively, these studies suggest that mtDNA mutations could contribute to cancer progression by increasing mitochondrial oxidative damage and changing cellular energy capacities.

3.4. Mouse Models of Oxidative Stress and Mitochondrial Dysfunction in Aging. Genetically engineered mouse models provide great systems to directly dissect the complex relationship between oxidative damage, mitochondrial dysfunction, and aging. Although it is difficult to manipulate mitochondrial genome, genetic engineering of nuclear genes that are involved in oxidative stress response and mitochondrial function has been utilized to study mitochondrial biology and aging.

Mammalian cells scavenge ROS to nontoxic forms through a sophisticated antioxidant defense that includes superoxide dismutase (SOD), catalase, and glutathione peroxidase. Genetic ablation of SOD2, which encodes a mitochondrial manganese SOD (MnSOD), leads to early postnatal death in mice accompanied by a dilated cardiomyopathy, metabolic acidosis, accumulation of lipid in liver and skeletal muscle, increased oxidative damage, and enzymatic abnormalities in mitochondria [216, 217]. Treatment of Sod $2^{-/-}$mice with a synthetic SOD mimetic not only rescues their mitochondrial defects in the liver, but also dramatically prolongs their survival [218]. Furthermore, heterozygous Sod $2^{+/-}$mice show evidence of decreased membrane potential, inhibition of respiration, and rapid accumulation of mitochondrial oxidative damage [219]. Mitochondrial oxidative stress induced by partial loss of SOD2 leads to an increase in proton leak, sensitization of the mitochondrial permeability transition pore and premature induction of apoptosis [219]. These studies clearly demonstrate that ROS generated in mitochondria play an important role in cell homeostasis and aging.

Conflicting results of the effect of increased SOD2 expression on aging are obtained using different SOD2 transgenic mouse strains [220-222]. A transgenic line carrying a human SOD2 transgene under the control of a human $\beta$-actin promoter shows protection against hyperoxic lung injury [220], reduction in mitochondrial superoxide in hippocampal neurons, and extended lifespan as the result of increased activity of MnSOD [221]. Another transgenic line carrying a $13-\mathrm{kb}$ mouse genomic fragment containing SOD2 [223] has a twofold increase in the activity of MnSOD [222].
Such level of SOD2 overexpression does not alter either lifespan or age-related pathology, even though these mice exhibit decreased lipid peroxidation, increased resistance against paraquat-induced oxidative stress, and decreased agerelated decline in mitochondrial ATP production [222]. The reason behind the different outcomes of these two SOD2 transgenic mice on lifespan is not clear, but may be related to different levels of SOD2 expression. The precise role of SOD2 in aging needs further investigation.

An important function of mitochondria is to produce ATP. Targeting genes involved in ATP production offers a great opportunity to study the role of mitochondrial function in aging. An example is a mouse model with targeted inactivation of adenine nucleotide translocator (ANT), a transporter protein that imports ADP and exports ATP from the mitochondria. Ant $1^{-/-}$mice exhibit classical physiological features of mitochondrial myopathy and hypertrophic cardiomyopathy in human, as evident of cardiac hypertrophy, an increase in succinate dehydrogenase and cytochrome $c$ oxidase activities, a degeneration of the contractile muscle fibers, and a massive proliferation of abnormal mitochondria in skeletal muscle [224]. The increase in mitochondrial abundance and volume in muscle of $A n t 1^{-/-}$mice is accompanied by upregulation of genes that are known to be involved in oxidative phosphorylation [225]. Consistently, mitochondrial $\mathrm{H}_{2} \mathrm{O}_{2}$ production increases in skeletal muscle and heart of $A n t 1^{-/-}$mice [226]. The Ant1-deficient mouse model provides strong evidence that a defect in mitochondrial energy metabolism can result in pathological disease [224].

IMMP2L protein is a subunit of a heterodimer complex of inner mitochondrial membrane peptidase that cleaves signal peptide from precursor or intermediate polypeptides after they reach the inner membrane of mitochondria [227, 228]. Mammalian IMMP2L has two known substrates, cytochrome c1 and glycerol phosphate dehydrogenase 2, both of which are involved in superoxide generation [229]. The Immp2l mutant mice have impaired processing of signal peptide of cytochrome $\mathrm{cl}$ and glycerol phosphate dehydrogenase 2 [230], and consequently show elevated level of superoxide ion, hyperpolarization of mitochondria, and increased oxidative stress in multiple organs. Furthermore, these Immp2l mutant mice exhibit multiple aging-related phenotypes, including wasting, sarcopenia, loss of subcutaneous fat, kyphosis, and ataxia [101]. These data provide a strong evidence that mitochondrial dysfunction is a driving force of accelerated aging.

\section{Conclusion}

Aging is a complex process involving a multitude of factors. Many studies have demonstrated that oxidative stress and mitochondrial dysfunction are two important factors contributing to the aging process. The importance of mitochondrial dynamics in aging is illustrated by its association with a growing number of age-associated pathogenesis. A better understanding of response to oxidative stress and mitochondrial dynamics will lead to new therapeutic 
approaches for the prevention or amelioration of age-associated degenerative diseases.

\section{Acknowledgments}

This work is supported by grants from the National Cancer Institute (R01CA131210) and The Ellison Medical Foundation (AG-NS-0347-06) to H. Zhang.

\section{References}

[1] L. Hayflick, "How and why we age," Experimental Gerontology, vol. 33, no. 7-8, pp. 639-653, 1998.

[2] T. B. L. Kirkwood, "Understanding the odd science of aging," Cell, vol. 120, no. 4, pp. 437-447, 2005.

[3] D. Harman, "Aging: a theory based on free radical and radiation chemistry," Journal of Gerontology, vol. 11, no. 3, pp. 298-300, 1956.

[4] B. Halliwell, "Reactive oxygen species in living systems: source, biochemistry, and role in human disease," American Journal of Medicine, vol. 91, no. 3, supplement 3, pp. 14S-22S, 1991.

[5] B. Chance, H. Sies, and A. Boveris, "Hydroperoxide metabolism in mammalian organs," Physiological Reviews, vol. 59, no. 3, pp. 527-605, 1979.

[6] R. G. Hansford, B. A. Hogue, and V. Mildaziene, "Dependence of $\mathrm{H}_{2} \mathrm{O}_{2}$ formation by rat heart mitochondria on substrate availability and donor age," Journal of Bioenergetics and Biomembranes, vol. 29, no. 1, pp. 89-95, 1997.

[7] W. Dröge, "Free radicals in the physiological control of cell function," Physiological Reviews, vol. 82, no. 1, pp. 47-95, 2002.

[8] I. Fridovich, "Superoxide radical and superoxide dismutases," Annual Review of Biochemistry, vol. 64, pp. 97-112, 1995.

[9] R. A. Weisiger and I. Fridovich, "Superoxide dismutase. Organelle specificity," Journal of Biological Chemistry, vol. 248, no. 10, pp. 3582-3592, 1973.

[10] R. A. Weisiger and I. Fridovich -, "Mitochondrial superoxide dismutase. Site of synthesis and intramitochondrial localization," Journal of Biological Chemistry, vol. 248, no. 13, pp. 4793-4796, 1973.

[11] A. Okado-Matsumoto and I. Fridovich, "Subcellular distribution of superoxide dismutases (SOD) in rat liver. $\mathrm{Cu}, \mathrm{Zn}$ SOD in mitochondria," Journal of Biological Chemistry, vol. 276, no. 42, pp. 38388-38393, 2001.

[12] L. A. Sturtz, K. Diekert, L. T. Jensen, R. Lill, and V. C. Culotta, "A fraction of yeast $\mathrm{Cu}, \mathrm{Zn}$-superoxide dismutase and its metallochaperone, CCS, localize to the intermembrane space of mitochondria. A physiological role for SOD1 in guarding against mitochondrial oxidative damage," Journal of Biological Chemistry, vol. 276, no. 41, pp. 38084-38089, 2001.

[13] J. F. Turrens, "Mitochondrial formation of reactive oxygen species," Journal of Physiology, vol. 552, no. 2, pp. 335-344, 2003.

[14] A. Holmgren, "Antioxidant function of thioredoxin and glutaredoxin systems," Antioxidants and Redox Signaling, vol. 2, no. 4, pp. 811-820, 2000.

[15] J. Nordberg and E. S. J. Arnér, "Reactive oxygen species, antioxidants, and the mammalian thioredoxin system," Free Radical Biology and Medicine, vol. 31, no. 11, pp. 1287-1312, 2001.
[16] S. P. Hussain, L. J. Hofseth, and C. C. Harris, "Radical causes of cancer," Nature Reviews Cancer, vol. 3, no. 4, pp. 276-285, 2003.

[17] J. Liu, W. Qu, and M. B. Kadiiska, "Role of oxidative stress in cadmium toxicity and carcinogenesis," Toxicology and Applied Pharmacology, vol. 238, no. 3, pp. 209-214, 2009.

[18] P. O'Neill and P. Wardman, "Radiation chemistry comes before radiation biology," International Journal of Radiation Biology, vol. 85, no. 1, pp. 9-25, 2009.

[19] T. J. McMillan, E. Leatherman, A. Ridley, J. Shorrocks, S. E. Tobi, and J. R. Whiteside, "Cellular effects of long wavelength UV light (UVA) in mammalian cells," Journal of Pharmacy and Pharmacology, vol. 60, no. 8, pp. 969-976, 2008.

[20] J. E. Klaunig and L. M. Kamendulis, "The Role of Oxidative Stress in Carcinogenesis," Annual Review of Pharmacology and Toxicology, vol. 44, pp. 239-267, 2004.

[21] R. C. Fry, T. J. Begley, and L. D. Samson, "Genomewide responses to DNA-damaging agents," Annual Review of Microbiology, vol. 59, pp. 357-377, 2005.

[22] C. J. Norbury and I. D. Hickson, "Cellular responses to DNA damage," Annual Review of Pharmacology and Toxicology, vol. 41, pp. 367-401, 2001.

[23] M. Spry, T. Scott, H. Pierce, and J. A. D'Orazio, "DNA repair pathways and hereditary cancer susceptibility syndromes," Frontiers in Bioscience, vol. 12, pp. 4191-4207, 2007.

[24] N. Ercal, H. Gurer-Orhan, and N. Aykin-Burns, "Toxic metals and oxidative stress part I: mechanisms involved in metal-induced oxidative damage," Current Topics in Medicinal Chemistry, vol. 1, no. 6, pp. 529-539, 2001.

[25] P. Kovacic and J. A. Osuna Jr., "Mechanisms of anti-cancer agents: emphasis on oxidative stress and electron transfer," Current Pharmaceutical Design, vol. 6, no. 3, pp. 277-309, 2000.

[26] D. A. Wink, I. Hanbauer, M. B. Grisham et al., "Chemical biology of nitric oxide: regulation and protective and toxic mechanisms," Current Topics in Cellular Regulation, vol. 34, pp. 159-187, 1996.

[27] T. Finkel and N. J. Holbrook, "Oxidants, oxidative stress and the biology of ageing," Nature, vol. 408, no. 6809, pp. 239$247,2000$.

[28] J. D. Lambeth, "NOX enzymes and the biology of reactive oxygen," Nature Reviews Immunology, vol. 4, no. 3, pp. 181189, 2004.

[29] M. T. Quinn, M. C. B. Ammons, and F. R. DeLeo, "The expanding role of NADPH oxidases in health and disease: no longer just agents of death and destruction," Clinical Science, vol. 111, no. 1, pp. 1-20, 2006.

[30] B. Chakravarti and D. N. Chakravarti, "Oxidative modification of proteins: age-related changes," Gerontology, vol. 53, no. 3, pp. 128-139, 2007.

[31] M. S. Cooke, M. D. Evans, M. Dizdaroglu, and J. Lunec, "Oxidative DNA damage: mechanisms, mutation, and disease," FASEB Journal, vol. 17, no. 10, pp. 1195-1214, 2003.

[32] M. D. Evans, M. Dizdaroglu, and M. S. Cooke, "Oxidative DNA damage and disease: induction, repair and significance," Mutation Research, vol. 567, no. 1, pp. 1-61, 2004.

[33] P. Filipcik, M. Cente, M. Ferencik, I. Hulin, and M. Novak, "The role of oxidative stress in the pathogenesis of Alzheimer's disease," Bratislavské Lekárske Listy, vol. 107, no. 9-10, pp. 384-394, 2006.

[34] P. Karihtala and Y. Soini, "Reactive oxygen species and antioxidant mechanisms in human tissues and their relation to malignancies," APMIS, vol. 115, no. 2, pp. 81-103, 2007. 
[35] H. E. Krokan, R. Standal, and G. Slupphaug, "DNA glycosylases in the base excision repair of DNA," Biochemical Journal, vol. 325, no. 1, pp. 1-16, 1997.

[36] M. Dizdaroglu, P. Jaruga, M. Birincioglu, and H. Rodriguez, "Free radical-induced damage to DNA: mechanisms and measurement," Free Radical Biology and Medicine, vol. 32, no. 11, pp. 1102-1115, 2002.

[37] A. P. Grollman and M. Moriya, "Mutagenesis by 8oxoguanine: an enemy within," Trends in Genetics, vol. 9, no. 7, pp. 246-249, 1993.

[38] A. Memisoglu and L. Samson, "Base excision repair in yeast and mammals," Mutation Research, vol. 451, no. 1-2, pp. 39$51,2000$.

[39] D. M. Wilson III, T. M. Sofinowski, and D. R. McNeill, "Repair mechanisms for oxidative DNA damage," Frontiers in Bioscience, vol. 8, pp. d963-d981, 2003.

[40] S. Maynard, S. H. Schurman, C. Harboe, N. C. de SouzaPinto, and V. A. Bohr, "Base excision repair of oxidative DNA damage and association with cancer and aging," Carcinogenesis, vol. 30, no. 1, pp. 2-10, 2009.

[41] M. F. Alexeyev, "Is there more to aging than mitochondrial DNA and reactive oxygen species?” FEBS Journal, vol. 276, no. 20 , pp. 5768-5787, 2009.

[42] H. Sies, "Strategies of antioxidant defense," European Journal of Biochemistry, vol. 215, pp. 213-219, 1993.

[43] M. V. Clément and S. Pervaiz, "Reactive oxygen intermediates regulate cellular response to apoptotic stimuli: an hypothesis," Free Radical Research, vol. 30, no. 4, pp. 247-252, 1999.

[44] A. S. Lundberg, W. C. Hahn, P. Gupta, and R. A. Weinberg, "Genes involved in senescence and immortalization," Current Opinion in Cell Biology, vol. 12, no. 6, pp. 705-709, 2000.

[45] R. H. Burdon, "Control of ceil proliferation by reactive oxygen species," Biochemical Society Transactions, vol. 24, no. 4, pp. 1028-1032, 1996.

[46] R. H. Burdon, "Superoxide and hydrogen peroxide in relation to mammalian cell proliferation," Free Radical Biology and Medicine, vol. 18, no. 4, pp. 775-794, 1995.

[47] M. Sawada and J. C. Carlson, "Changes in superoxide radical and lipid peroxide formation in the brain, heart and liver during the lifetime of the rat," Mechanisms of Ageing and Development, vol. 41, no. 1-2, pp. 125-137, 1987.

[48] R. S. Sohal and B. H. Sohal, "Hydrogen peroxide release by mitochondria increases during aging," Mechanisms of Ageing and Development, vol. 57, no. 2, pp. 187-202, 1991.

[49] R. S. Sohal and A. Dubey, "Mitochondrial oxidative damage, hydrogen peroxide release, and aging," Free Radical Biology and Medicine, vol. 16, no. 5, pp. 621-626, 1994.

[50] F. Capel, V. Rimbert, D. Lioger et al., "Due to reverse electron transfer, mitochondrial $\mathrm{H}_{2} \mathrm{O}_{2}$ release increases with age in human vastus lateralis muscle although oxidative capacity is preserved," Mechanisms of Ageing and Development, vol. 126, no. 4, pp. 505-511, 2005.

[51] C. G. Fraga, M. K. Shigenaga, J. W. Park, P. Degan, and B. N. Ames, "Oxidative damage to DNA during aging: 8-Hydroxy2'-deoxyguanosine in rat organ DNA and urine," Proceedings of the National Academy of Sciences of the United States of America, vol. 87, no. 12, pp. 4533-4537, 1990.

[52] M. L. Hamilton, H. Van Remmen, J. A. Drake et al., "Does oxidative damage to DNA increase with age?" Proceedings of the National Academy of Sciences of the United States of America, vol. 98, no. 18, pp. 10469-10474, 2001.

[53] C. N. Oliver, B. W. Ahn, and E. J. Moerman, "Age-related changes in oxidized proteins," Journal of Biological Chemistry, vol. 262, no. 12, pp. 5488-5491, 1987.
[54] P. L. Larsen, "Aging and resistance to oxidative damage in Caenorhabditis elegans," Proceedings of the National Academy of Sciences of the United States of America, vol. 90, no. 19, pp. 8905-8909, 1993.

[55] N. Ishii, "Oxidative stress and aging in Caenorhabditis elegans," Free Radical Research, vol. 33, no. 6, pp. 857-864, 2000.

[56] S. Elchuri, T. D. Oberley, W. Qi et al., "CuZnSOD deficiency leads to persistent and widespread oxidative damage and hepatocarcinogenesis later in life," Oncogene, vol. 24, no. 3, pp. 367-380, 2005.

[57] W. C. Orr and R. S. Sohal, "Extension of life-span by overexpression of superoxide dismutase and catalase in Drosophila melanogaster," Science, vol. 263, no. 5150, pp. 1128-1130, 1994.

[58] S. Melov, J. Ravenscroft, S. Malik et al., "Extension of lifespan with superoxide dismutase/catalase mimetics," Science, vol. 289, no. 5484, pp. 1567-1569, 2000.

[59] L. Erker, R. Schubert, H. Yakushiji et al., "Cancer chemoprevention by the antioxidant tempol acts partially via the p53 tumor suppressor," Human Molecular Genetics, vol. 14, no. 12, pp. 1699-1708, 2005.

[60] S. E. Schriner, N. J. Linford, G. M. Martin et al., "Medecine: extension of murine life span by overexpression of catalase targeted to mitochondria," Science, vol. 308, no. 5730, pp. 1909-1911, 2005.

[61] Y. Xie, H. Yang, C. Cunanan et al., "Deficiencies in mouse Myh and Ogg1 result in tumor predisposition and $G$ to $\mathrm{T}$ mutations in codon 12 of the K-ras oncogene in lung tumors," Cancer Research, vol. 64, no. 9, pp. 3096-3102, 2004.

[62] J. Lapointe and S. Hekimi, "When a theory of aging ages badly," Cellular and Molecular Life Sciences, vol. 67, no. 1, pp. $1-8,2010$.

[63] H. Van Remmen, Y. Ikeno, M. Hamilton et al., "Lifelong reduction in MnSOD activity results in increased DNA damage and higher incidence of cancer but does not accelerate aging," Physiological Genomics, vol. 16, pp. 29-37, 2003.

[64] T. T. Huang, E. J. Carlson, A. M. Gillespie, Y. Shi, and C. J. Epstein, "Ubiquitous overexpression of CuZn superoxide dismutase does not extend life span in mice," Journals of Gerontology A, vol. 55, no. 1, pp. B5-B9, 2000.

[65] X. Chen, H. Liang, H. Van Remmen, J. Vijg, and A. Richardson, "Catalase transgenic mice: characterization and sensitivity to oxidative stress," Archives of Biochemistry and Biophysics, vol. 422, no. 2, pp. 197-210, 2004.

[66] Q. Ran, H. Liang, Y. Ikeno et al., "Reduction in glutathione peroxidase 4 increases life span through increased sensitivity to apoptosis," Journals of Gerontology A, vol. 62, no. 9, pp. 932-942, 2007.

[67] B. Andziak, T. P. O’Connor, W. Qi et al., "High oxidative damage levels in the longest-living rodent, the naked molerat," Aging Cell, vol. 5, no. 6, pp. 463-471, 2006.

[68] R. S. Sohal, S. Kamzalov, N. Sumien et al., "Effect of coenzyme Q10 intake on endogenous coenzyme Q content, mitochondrial electron transport chain, antioxidative defenses, and life span of mice," Free Radical Biology and Medicine, vol. 40, no. 3, pp. 480-487, 2006.

[69] R. M. Howes, "The free radical fantasy: a panoply of paradoxes," Annals of the New York Academy of Sciences, vol. 1067, no. 1, pp. 22-26, 2006.

[70] G. Bjelakovic, D. Nikolova, L. L. Gluud, R. G. Simonetti, and C. Gluud, "Mortality in randomized trials of antioxidant supplements for primary and secondary prevention: 
systematic review and meta-analysis," Journal of the American Medical Association, vol. 297, no. 8, pp. 842-857, 2007.

[71] L. Hayflick and P. S. Moorhead, "The serial cultivation of human diploid cell strains," Experimental Cell Research, vol. 25, no. 3, pp. 585-621, 1961.

[72] L. Hayflick, "The cell biology of human aging," New England Journal of Medicine, vol. 295, no. 23, pp. 1302-1308, 1976.

[73] J. Campisi, "Senescent cells, tumor suppression, and organismal aging: good citizens, bad neighbors," Cell, vol. 120, no. 4, pp. 513-522, 2005.

[74] N. E. Sharpless and R. A. DePinho, "Telomeres, stem cells, senescence, and cancer," Journal of Clinical Investigation, vol. 113, no. 2, pp. 160-168, 2004.

[75] J. F. Passos, G. Saretzki, S. Ahmed et al., "Mitochondrial dysfunction accounts for the stochastic heterogeneity in telomere-dependent senescence," PLoS Biology, vol. 5, no. 5, article e110, 2007.

[76] Q. Chen, A. Fischer, J. D. Reagan, L. J. Yan, and B. N. Ames, "Oxidative DNA damage and senescence of human diploid fibroblast cells," Proceedings of the National Academy of Sciences of the United States of America, vol. 92, no. 10, pp. 4337-4341, 1995.

[77] N. Sitte, K. Merker, T. Von Zglinicki, and T. Grune, "Protein oxidation and degradation during proliferative senescence of human MRC-5 fibroblasts," Free Radical Biology and Medicine, vol. 28, no. 5, pp. 701-708, 2000.

[78] K. Itahana, Y. Zou, Y. Itahana et al., "Control of the replicative life span of human fibroblasts by p16 and the polycomb protein Bmi-1," Molecular and Cellular Biology, vol. 23, no. 1, pp. 389-401, 2003.

[79] V. Serra, T. Von Zglinicki, M. Lorenz, and G. Saretzki, "Extracellular superoxide dismutase is a major antioxidant in human fibroblasts and slows telomere shortening," Journal of Biological Chemistry, vol. 278, no. 9, pp. 6824-6830, 2003.

[80] T. Lu and T. Finkel, "Free radicals and senescence," Experimental Cell Research, vol. 314, no. 9, pp. 1918-1922, 2008.

[81] T. L. Parkes, A. J. Elia, D. Dickinson, A. J. Hilliker, J. P. Phillips, and G. L. Boulianne, "Extension of Drosophila lifespan by overexpression of human SOD1 in motorneurons," Nature Genetics, vol. 19, no. 2, pp. 171-174, 1998.

[82] W. E. Wright and J. W. Shay, "Cellular senescence as a tumor-protection mechanism: the essential role of counting," Current Opinion in Genetics and Development, vol. 11, no. 1, pp. 98-103, 2001.

[83] A. G. Bodnar, M. Ouellette, M. Frolkis et al., "Extension of life-span by introduction of telomerase into normal human cells," Science, vol. 279, no. 5349, pp. 349-352, 1998.

[84] T. Richter and T. Von Zglinicki, "A continuous correlation between oxidative stress and telomere shortening in fibroblasts," Experimental Gerontology, vol. 42, no. 11, pp. 1039 $1042,2007$.

[85] V. A. Szalai, M. J. Singer, and H. H. Thorp, "Site-specific probing of oxidative reactivity and telomerase function using 7,8-dihydro-8-oxoguanine in telomeric DNA," Journal of the American Chemical Society, vol. 124, no. 8, pp. 1625-1631, 2002.

[86] J. Haendeler, J. Hoffmann, J. F. Diehl et al., "Antioxidants inhibit nuclear export of telomerase reverse transcriptase and delay replicative senescence of endothelial cells," Circulation Research, vol. 94, no. 6, pp. 768-775, 2004.

[87] P. L. Opresko, J. Fan, S. Danzy, D. M. Wilson III, and V. A. Bohr, "Oxidative damage in telomeric DNA disrupts recognition by TRF1 and TRF2," Nucleic Acids Research, vol. 33, no. 4, pp. 1230-1239, 2005.
[88] W. Palm and T. De Lange, "How shelterin protects mammalian telomeres," Annual Review of Genetics, vol. 42, pp. 301-334, 2008.

[89] G. Achanta and P. Huang, "Role of p53 in sensing oxidative DNA damage in response to reactive oxygen speciesgenerating agents," Cancer Research, vol. 64, no. 17, pp. 62336239, 2004.

[90] K. Fujita, I. Horikawa, A. M. Mondal et al., "Positive feedback between 553 and TRF2 during telomere-damage signalling and cellular senescence," Nature Cell Biology, vol. 12, no. 12, pp. 1205-1212, 2010.

[91] D. J. Rossi, C. H. M. Jamieson, and I. L. Weissman, "Stems cells and the pathways to aging and cancer," Cell, vol. 132, no. 4, pp. 681-696, 2008.

[92] J. Chen, C. M. Astle, and D. E. Harrison, "Development and aging of primitive hematopoietic stem cells in BALB/cBy mice," Experimental Hematology, vol. 27, no. 5, pp. 928-935, 1999.

[93] J. Chen, C. M. Astle, and D. E. Harrison, "Genetic regulation of primitive hematopoietic stem cell senescence," Experimental Hematology, vol. 28, no. 4, pp. 442-450, 2000.

[94] D. J. Rossi, D. Bryder, J. M. Zahn et al., "Cell intrinsic alterations underlie hematopoietic stem cell aging," Proceedings of the National Academy of Sciences of the United States of America, vol. 102, no. 26, pp. 9194-9199, 2005.

[95] K. Ito, A. Hirao, F. Arai et al., "Regulation of oxidative stress by ATM is required for self-renewal of haematopoietic stem cells," Nature, vol. 431, no. 7011, pp. 997-1002, 2004.

[96] Z. Tothova, R. Kollipara, B. J. Huntly et al., "FoxOs are critical mediators of hematopoietic stem cell resistance to physiologic oxidative stress," Cell, vol. 128, no. 2, pp. 325339, 2007.

[97] S. Yalcin, X. Zhang, J. P. Luciano et al., "Foxo3 is essential for the regulation of ataxia telangiectasia mutated and oxidative stress-mediated homeostasis of hematopoietic stem cells," Journal of Biological Chemistry, vol. 283, no. 37, pp. 2569225705, 2008.

[98] K. Miyamoto, K. Y. Araki, K. Naka et al., "Foxo3a is essential for maintenance of the hematopoietic stem cell pool," Cell Stem Cell, vol. 1, no. 1, pp. 101-112, 2007.

[99] E. Nitta, M. Yamashita, K. Hosokawa et al., "Telomerase reverse transcriptase protects ATM-deficient hematopoietic stem cells from ROS-induced apoptosis through a telomereindependent mechanism," Blood, vol. 117, no. 16, pp. 41694180, 2011.

[100] S. Yalcin, D. Marinkovic, S. K. Mungamuri et al., "ROSmediated amplification of AKT/mTOR signalling pathway leads to myeloproliferative syndrome in Foxo3-/- mice," EMBO Journal, vol. 29, no. 24, pp. 4118-4131, 2010.

[101] S. K. George, Y. Jiao, C. E. Bishop, and B. Lu, "Mitochondrial peptidase IMMP2L mutation causes early onset of ageassociated disorders and impairs adult stem cell self-renewal," Aging Cell, vol. 10, no. 4, pp. 584-594, 2011.

[102] Y. Y. Jang and S. J. Sharkis, "A low level of reactive oxygen species selects for primitive hematopoietic stem cells that may reside in the low-oxygenic niche," Blood, vol. 110, no. 8, pp. 3056-3063, 2007.

[103] D. J. Rossi, D. Bryder, J. Seita, A. Nussenzweig, J. Hoeijmakers, and I. L. Weissman, "Deficiencies in DNA damage repair limit the function of haematopoietic stem cells with age," Nature, vol. 447, no. 7145, pp. 725-729, 2007.

[104] D. Harman, “The biologic clock: the mitochondria?” Journal of the American Geriatrics Society, vol. 20, no. 4, pp. 145-147, 1972. 
[105] C. Richter, "Reactive oxygen and DNA damage in mitochondria," Mutation Research, vol. 275, no. 3-6, pp. 249-255, 1992.

[106] M. K. Shigenaga, T. M. Hagen, and B. N. Ames, "Oxidative damage and mitochondrial decay in aging," Proceedings of the National Academy of Sciences of the United States of America, vol. 91, no. 23, pp. 10771-10778, 1994.

[107] S. Agarwal and R. S. Sohal, "DNA oxidative damage and life expectancy in houseflies," Proceedings of the National Academy of Sciences of the United States of America, vol. 91, no. 25, pp. 12332-12335, 1994.

[108] C. Richter, J. W. Park, and B. N. Ames, "Normal oxidative damage to mitochondrial and nuclear DNA is extensive," Proceedings of the National Academy of Sciences of the United States of America, vol. 85, no. 17, pp. 6465-6467, 1988.

[109] P. Mecocci, U. MacGarvey, A. E. Kaufman et al., "Oxidative damage to mitochondrial DNA shows marked agedependent increases in human brain," Annals of Neurology, vol. 34, no. 4, pp. 609-616, 1993.

[110] M. Hayakawa, T. Ogawa, S. Sugiyama, M. Tanaka, and T. Ozawa, "Massive conversion of guanosine to 8-hydroxyguanosine in mouse liver mitochondrial DNA by administration of azidothymidine," Biochemical and Biophysical Research Communications, vol. 176, no. 1, pp. 87-93, 1991.

[111] B. N. Ames, M. K. Shigenaga, and T. M. Hagen, "Oxidants, antioxidants, and the degenerative diseases of aging," Proceedings of the National Academy of Sciences of the United States of America, vol. 90, no. 17, pp. 7915-7922, 1993.

[112] J. G. De La Asuncion, A. Millan, R. Pla et al., "Mitochondrial glutathione oxidation correlates with age-associated oxidative damage to mitochondrial DNA," FASEB Journal, vol. 10, no. 2, pp. 333-338, 1996.

[113] J. H. Santos, B. S. Mandavilli, and B. Van Houten, "Measuring oxidative mtDNA damage and repair using quantitative PCR," Methods in Molecular Biology, vol. 197, pp. 159-176, 2002.

[114] J. Miquel, A. C. Economos, J. Fleming, and J. E. Johnson Jr., "Mitochondrial role in cell aging," Experimental Gerontology, vol. 15, no. 6, pp. 575-591, 1980.

[115] M. Falkenberg, N. G. Larsson, and C. M. Gustafsson, "DNA replication and transcription in mammalian mitochondria," Annual Review of Biochemistry, vol. 76, pp. 679-699, 2007.

[116] J. E. Fleming, J. Miquel, and S. F. Cottrell, "Is cell aging caused by respiration-dependent injury to the mitochondrial genome?” Gerontology, vol. 28, no. 1, pp. 44-53, 1982.

[117] A. Chomyn and G. Attardi, "MtDNA mutations in aging and apoptosis," Biochemical and Biophysical Research Communications, vol. 304, no. 3, pp. 519-529, 2003.

[118] A. Hiona and C. Leeuwenburgh, "The role of mitochondrial DNA mutations in aging and sarcopenia: implications for the mitochondrial vicious cycle theory of aging," Experimental Gerontology, vol. 43, no. 1, pp. 24-33, 2008.

[119] R. Yamaguchi and G. Perkins, "Dynamics of mitochondrial structure during apoptosis and the enigma of Opa1," Biochimica et Biophysica Acta, vol. 1787, no. 8, pp. 963-972, 2009.

[120] M. Mather and H. Rottenberg, "Aging enhances the activation of the permeability transition pore in mitochondria," Biochemical and Biophysical Research Communications, vol. 273, no. 2, pp. 603-608, 2000.

[121] H. Rottenberg and S. Wu, "Mitochondrial dysfunction in lymphocytes from old mice: enhanced activation of the permeability transition," Biochemical and Biophysical Research Communications, vol. 240, no. 1, pp. 68-74, 1997.
[122] L. J. Yan and R. S. Sohal, "Mitochondrial adenine nucleotide translocase is modified oxidatively during aging," Proceedings of the National Academy of Sciences of the United States of America, vol. 95, no. 22, pp. 12896-12901, 1998.

[123] Y. Zhang and B. Herman, "Ageing and apoptosis," Mechanisms of Ageing and Development, vol. 123, no. 4, pp. 245-260, 2002.

[124] A. Trifunovic, A. Wredenberg, M. Falkenberg et al., "Premature ageing in mice expressing defective mitochondrial DNA polymerase," Nature, vol. 429, no. 6990, pp. 417-423, 2004.

[125] C. C. Kujoth, A. Hiona, T. D. Pugh et al., "Medicine: mitochondrial DNA mutations, oxidative stress, and apoptosis in mammalian aging," Science, vol. 309, no. 5733, pp. 481-484, 2005.

[126] J. L. Mott, D. Zhang, M. Stevens, S. W. Chang, G. Denniger, and H. P. Zassenhaus, "Oxidative stress is not an obligate mediator of disease provoked by mitochondrial DNA mutations," Mutation Research, vol. 474, no. 1-2, pp. 35-45, 2001.

[127] H. Kasamatsu, D. L. Robberson, and J. Vinograd, "A novel closed-circular mitochondrial DNA with properties of a replicating intermediate," Proceedings of the National Academy of Sciences of the United States of America, vol. 68, no. 9, pp. 2252-2257, 1971.

[128] C. D. Calloway, R. L. Reynolds, G. L. Herrin, and W. W. Anderson, "The frequency of heteroplasmy in the HVII region of mtDNA differs across tissue types and increases with age," American Journal of Human Genetics, vol. 66, no. 4, pp. 1384-1397, 2000.

[129] R. Del Bo, A. Bordoni, F. M. Boneschi et al., "Evidence and age-related distribution of mtDNA D-loop point mutations in skeletal muscle from healthy subjects and mitochondrial patients," Journal of the Neurological Sciences, vol. 202, no. 12, pp. 85-91, 2002.

[130] Y. Michikawa, F. Mazzucchelli, N. Bresolin, G. Scarlato, and G. Attardi, "Aging-dependent large accumulation of point mutations in the human mtDNA control region for replication," Science, vol. 286, no. 5440, pp. 774-779, 1999.

[131] C. Thèves, C. Keyser-Tracqui, E. Crubézy, J.-P. Salles, B. Ludes, and N. Telmon, "Detection and quantification of the age-related point mutation $\mathrm{A} 189 \mathrm{G}$ in the human mitochondrial DNA," Journal of Forensic Sciences, vol. 51, no. 4, pp. 865-873, 2006.

[132] Y. Wang, Y. Michikawa, C. Mallidis et al., "Muscle-specific mutations accumulate with aging in critical human mtDNA control sites for replication," Proceedings of the National Academy of Sciences of the United States of America, vol. 98, no. 7, pp. 4022-4027, 2001.

[133] L. Piko, A. J. Hougham, and K. J. Bulpitt, "Studies of sequence heterogeneity of mitochondrial DNA from rat and mouse tissues: evidence for an increased frequency of deletions/additions with aging," Mechanisms of Ageing and Development, vol. 43, no. 3, pp. 279-293, 1988.

[134] G. A. Cortopassi and N. Arnheim, "Detection of a specific mitochondrial DNA deletion in tissues of older humans," Nucleic Acids Research, vol. 18, no. 23, pp. 6927-6933, 1990.

[135] W. Sato, M. Tanaka, K. Ohno, T. Yamamoto, G. Takada, and T. Ozawa, "Multiple populations of deleted mitochondrial DNA detected by a novel gene amplification method," Biochemical and Biophysical Research Communications, vol. 162, no. 2, pp. 664-672, 1989.

[136] N. W. Soong, D. R. Hinton, G. Cortopassi, and N. Arnheim, "Mosaicism for a specific somatic mitochondrial DNA mutation in adult human brain," Nature Genetics, vol. 2, no. 4, pp. 318-323, 1992. 
[137] M. Corral-Debrinski, T. Horton, M. T. Lott, J. M. Shoffner, M. F. Beal, and D. C. Wallace, "Mitochondrial DNA deletions in human brain: regional variability and increase with advanced age," Nature Genetics, vol. 2, no. 4, pp. 324-329, 1992.

[138] S. S. Chung, R. Weindruch, S. R. Schwarze, D. I. McKenzie, and J. M. Aiken, "Multiple age-associated mitochondrial DNA deletions in skeletal muscle of mice," Aging, vol. 6, no. 3, pp. 193-200, 1994.

[139] C. M. Lee, S. S. Chung, J. M. Kaczkowski, R. Weindruch, and J. M. Aiken, "Multiple mitochondrial DNA deletions associated with age in skeletal muscle of rhesus monkeys," Journals of Gerontology, vol. 48, no. 6, pp. B201-B205, 1993.

[140] C. M. Lee, M. E. Lopez, R. Weindruch, and J. M. Aiken, "Association of age-related mitochondrial abnormalities with skeletal muscle fiber atrophy," Free Radical Biology and Medicine, vol. 25, no. 8, pp. 964-972, 1998.

[141] S. Melov, G. J. Lithgow, D. R. Fischer, P. M. Tedesco, and T. E. Johnson, "Increased frequency of deletions in the mitochondrial genome with age of Caenorhabditis elegans," Nucleic Acids Research, vol. 23, no. 8, pp. 1419-1425, 1995.

[142] S. Melova, J. A. Schneider, P. E. Coskun, D. A. Bennett, and D. C. Wallace, "Mitochondrial DNA rearrangements in aging human brain and in situ PCR of mtDNA," Neurobiology of Aging, vol. 20, no. 5, pp. 565-571, 1999.

[143] S. Melov, J. M. Shoffner, A. Kaufman, and D. C. Wallace, "Marked increase in the number and variety of mitochondrial DNA rearrangements in aging human skeletal muscle," Nucleic Acids Research, vol. 23, no. 20, pp. 4122-4126, 1995.

[144] S. R. Schwarze, C. M. Lee, S. S. Chung, E. B. Roecker, R. Weindruch, and J. M. Aiken, "High levels of mitochondrial DNA deletions in skeletal muscle of old rhesus monkeys," Mechanisms of Ageing and Development, vol. 83, no. 2, pp. 91-101, 1995.

[145] C. Zhang, A. Baumer, R. J. Maxwell, A. W. Linnane, and P. Nagley, "Multiple mitochondrial DNA deletions in an elderly human individual," FEBS Letters, vol. 297, no. 1-2, pp. 34-38, 1992.

[146] D. L. Robberson and D. A. Clayton, "Replication of mitochondrial DNA in mouse $\mathrm{L}$ cells and their thymidine kinase-derivatives: displacement replication on a covalently-closed circular template," Proceedings of the National Academy of Sciences of the United States of America, vol. 69, no. 12, pp. 3810-3814, 1972.

[147] T. Yasukawa, A. Reyes, T. J. Cluett et al., "Replication of vertebrate mitochondrial DNA entails transient ribonucleotide incorporation throughout the lagging strand," EMBO Journal, vol. 25, no. 22, pp. 5358-5371, 2006.

[148] I. J. Holt, H. E. Lorimer, and H. T. Jacobs, "Coupled leadingand lagging-strand synthesis of mammalian mitochondrial DNA," Cell, vol. 100, no. 5, pp. 515-524, 2000.

[149] K. J. Krishnan, A. K. Reeve, D. C. Samuels et al., "What causes mitochondrial DNA deletions in human cells?" Nature Genetics, vol. 40, no. 3, pp. 275-279, 2008.

[150] J. E. Haber, "Partners and pathways-repairing a doublestrand break," Trends in Genetics, vol. 16, no. 6, pp. 259-264, 2000.

[151] A. W. Linnane, C. Zhang, A. Baumer, and P. Nagley, "Mitochondrial DNA mutation and the ageing process: bioenergy and pharmacological intervention," Mutation Research, vol. 275, no. 3-6, pp. 195-208, 1992.

[152] N. Arnheim and G. Cortopassi, "Deleterious mitochondrial DNA mutations accumulate in aging human tissues," Mutation Research, vol. 275, no. 3-6, pp. 157-167, 1992.
[153] M. Hayakawa, K. Hattori, S. Sugiyama, and T. Ozawa, "Ageassociated oxygen damage and mutations in mitochondrial DNA in human hearts," Biochemical and Biophysical Research Communications, vol. 189, no. 2, pp. 979-985, 1992.

[154] C. Meissner, P. Bruse, S. A. Mohamed et al., "The 4977 bp deletion of mitochondrial DNA in human skeletal muscle, heart and different areas of the brain: a useful biomarker or more?" Experimental Gerontology, vol. 43, no. 7, pp. 645-652, 2008.

[155] T.-C. Yen, J.-H. Su, K.-L. King, and Y.-H. Wei, "Ageingassociated $5 \mathrm{~kb}$ deletion in human liver mitochondrial DNA," Biochemical and Biophysical Research Communications, vol. 178, no. 1, pp. 124-131, 1991.

[156] R. Barazzoni, K. R. Short, and K. S. Nair, "Effects of aging on mitochondrial DNA copy number and cytochrome $\mathrm{c}$ oxidase gene expression in rat skeletal muscle, liver, and heart," Journal of Biological Chemistry, vol. 275, no. 5, pp. 3343-3347, 2000.

[157] S. Welle, K. Bhatt, B. Shah, N. Needler, J. M. Delehanty, and C. A. Thornton, "Reduced amount of mitochondrial DNA in aged human muscle," Journal of Applied Physiology, vol. 94, no. 4, pp. 1479-1484, 2003.

[158] K. R. Short, M. L. Bigelow, J. Kahl et al., "Decline in skeletal muscle mitochondrial function with aging in humans," Proceedings of the National Academy of Sciences of the United States of America, vol. 102, no. 15, pp. 5618-5623, 2005.

[159] F. J. Miller, F. L. Rosenfeldt, C. Zhang, A. W. Linnane, and P. Nagley, "Precise determination of mitochondrial DNA copy number in human skeletal and cardiac muscle by a PCRbased assay: lack of change of copy number with age," Nucleic Acids Research, vol. 31, no. 11, article e61, 2003.

[160] T. Frahm, S. A. Mohamed, P. Bruse, C. Gemünd, M. Oehmichen, and C. Meissner, "Lack of age-related increase of mitochondrial DNA amount in brain, skeletal muscle and human heart," Mechanisms of Ageing and Development, vol. 126, no. 11, pp. 1192-1200, 2005.

[161] M. Masuyama, R. Iida, H. Takatsuka, T. Yasuda, and T. Matsuki, "Quantitative change in mitochondrial DNA content in various mouse tissues during aging," Biochimica et Biophysica Acta, vol. 1723, no. 1-3, pp. 302-308, 2005.

[162] I. R. Lanza, D. K. Short, K. R. Short et al., "Endurance exercise as a countermeasure for aging," Diabetes, vol. 57, no. 11, pp. 2933-2942, 2008.

[163] F. W. Booth and D. B. Thomason, "Molecular and cellular adaptation of muscle in response to exercise: perspectives of various models," Physiological Reviews, vol. 71, no. 2, pp. 541-585, 1991.

[164] L. S. Chow, L. J. Greenlund, Y. W. Asmann et al., "Impact of endurance training on murine spontaneous activity, muscle mitochondrial DNA abundance, gene transcripts, and function," Journal of Applied Physiology, vol. 102, no. 3, pp. 1078-1089, 2007.

[165] S. DiMauro and A. L. Andreu, "Mutations in mtDNA: are we scraping the bottom of the barrel?" Brain Pathology, vol. 10, no. 3, pp. 431-441, 2000.

[166] D. C. Wallace, "Mouse models for mitochondrial disease," American Journal of Medical Genetics, vol. 106, no. 1, pp. 7193, 2001.

[167] G. L. Wenk, "Neuropathologic changes in Alzheimer's disease," Journal of Clinical Psychiatry, vol. 64, supplement 9, pp. 7-10, 2003.

[168] J. P. Blass and G. E. Gibson, "The role of oxidative abnormalities in the pathophysiology of Alzheimer's disease," Revue Neurologique, vol. 147, no. 6-7, pp. 513-525, 1991. 
[169] J. P. Blass, A. C. Baker, L. W. Ko, and R. S. Black, "Induction of Alzheimer antigens by an uncoupler of oxidative phosphorylation," Archives of Neurology, vol. 47, no. 8, pp. 864-869, 1990.

[170] K. Hirai, G. Aliev, A. Nunomura et al., "Mitochondrial abnormalities in Alzheimer's disease," Journal of Neuroscience, vol. 21, no. 9, pp. 3017-3023, 2001.

[171] S. M. Cardoso, M. T. Proença, S. Santos, I. Santana, and C. R. Oliveira, "Cytochrome c oxidase is decreased in Alzheimer's disease platelets," Neurobiology of Aging, vol. 25, no. 1, pp. 105-110, 2004.

[172] S. J. Kish, C. Bergeron, A. Rajput et al., "Brain cytochrome oxidase in Alzheimer's disease," Journal of Neurochemistry, vol. 59, no. 2, pp. 776-779, 1992.

[173] E. M. Mutisya, A. C. Bowling, and M. F. Beal, "Cortical cytochrome oxidase activity is reduced in Alzheimer's disease," Journal of Neurochemistry, vol. 63, no. 6, pp. 21792184, 1994.

[174] A. Wood-Kaczmar, S. Gandhi, and N. W. Wood, "Understanding the molecular causes of Parkinson's disease," Trends in Molecular Medicine, vol. 12, no. 11, pp. 521-528, 2006.

[175] J. T. Greenamyre and T. G. Hastings, "Parkinsons-divergent causes convergent mechanisms," Science, vol. 304, no. 5674, pp. 1120-1122, 2004.

[176] V. M. Mann, J. M. Cooper, S. E. Daniel et al., "Complex I, iron, and ferritin in Parkinson's disease substantia nigra," Annals of Neurology, vol. 36, no. 6, pp. 876-881, 1994.

[177] J. W. Langston, L. S. Forno, J. Tetrud, A. G. Reeves, J. A. Kaplan, and D. Karluk, "Evidence of active nerve cell degeneration in the substantia nigra of humans years after 1-methyl-4-phenyl-1,2,3,6-tetrahydropyridine exposure," Annals of Neurology, vol. 46, no. 4, pp. 598-605, 1999.

[178] W. Dauer and S. Przedborski, "Parkinson's disease: mechanisms and models," Neuron, vol. 39, no. 6, pp. 889-909, 2003.

[179] H. Chen and D. C. Chan, "Mitochondrial dynamics-fusion, fission, movement, and mitophagy-in neurodegenerative diseases," Human Molecular Genetics, vol. 18, no. 2, pp. R169176, 2009.

[180] M. W. Dodson and M. Guo, "Pink1, Parkin, DJ-1 and mitochondrial dysfunction in Parkinson's disease," Current Opinion in Neurobiology, vol. 17, no. 3, pp. 331-337, 2007.

[181] E. Rogaeva, J. Johnson, A. E. Lang et al., "Analysis of the PINK1 gene in a large cohort of cases with Parkinson disease," Archives of Neurology, vol. 61, no. 12, pp. 1898-1904, 2004.

[182] E. M. Valente, P. M. Abou-Sleiman, V. Caputo et al., "Hereditary early-onset Parkinson's disease caused by mutations in PINK1," Science, vol. 304, no. 5674, pp. 1158-1160, 2004.

[183] T. Kitada, S. Asakawa, N. Hattori et al., "Mutations in the parkin gene cause autosomal recessive juvenile parkinsonism," Nature, vol. 392, no. 6676, pp. 605-608, 1998.

[184] Y. Yang, S. Gehrke, Y. Imai et al., "Mitochondrial pathology and muscle and dopaminergic neuron degeneration caused by inactivation of Drosophila Pink1 is rescued by Parkin," Proceedings of the National Academy of Sciences of the United States of America, vol. 103, no. 28, pp. 10793-10798, 2006.

[185] J. Park, S. B. Lee, S. Lee et al., "Mitochondrial dysfunction in Drosophila PINK1 mutants is complemented by parkin," Nature, vol. 441, no. 7097, pp. 1157-1161, 2006.

[186] I. E. Clark, M. W. Dodson, C. Jiang et al., "Drosophila pink1 is required for mitochondrial function and interacts genetically with parkin," Nature, vol. 441, no. 7097, pp. 1162-1166, 2006.

[187] N. Exner, B. Treske, D. Paquet et al., "Loss-of-function of human PINK1 results in mitochondrial pathology and can be rescued by parkin," Journal of Neuroscience, vol. 27, no. 45, pp. 12413-12418, 2007.

[188] M. E. MacDonald, C. M. Ambrose, M. P. Duyao et al., "A novel gene containing a trinucleotide repeat that is expanded and unstable on Huntington's disease chromosomes," Cell, vol. 72, no. 6, pp. 971-983, 1993.

[189] E. Bossy-Wetzel, A. Petrilli, and A. B. Knott, "Mutant huntingtin and mitochondrial dysfunction," Trends in Neurosciences, vol. 31, no. 12, pp. 609-616, 2008.

[190] A. L. Orr, S. Li, C. E. Wang et al., "N-terminal mutant huntingtin associates with mitochondria and impairs mitochondrial trafficking," Journal of Neuroscience, vol. 28, no. 11, pp. 2783-2792, 2008.

[191] A. V. Panov, C. A. Gutekunst, B. R. Leavitt et al., "Early mitochondrial calcium defects in Huntington's disease are a direct effect of polyglutamines," Nature Neuroscience, vol. 5, no. 8, pp. 731-736, 2002.

[192] F. Squitieri, M. Cannella, G. Sgarbi et al., "Severe ultrastructural mitochondrial changes in lymphoblasts homozygous for Huntington disease mutation," Mechanisms of Ageing and Development, vol. 127, no. 2, pp. 217-220, 2006.

[193] M. T. Lin and M. F. Beal, "Mitochondrial dysfunction and oxidative stress in neurodegenerative diseases," Nature, vol. 443, no. 7113, pp. 787-795, 2006.

[194] E. H. Kim, S. Sohn, H. J. Kwon et al., "Sodium selenite induces superoxide-mediated mitochondrial damage and subsequent autophagic cell death in malignant glioma cells," Cancer Research, vol. 67, no. 13, pp. 6314-6324, 2007.

[195] R. A. Kirkland, R. M. Adibhatla, J. F. Hatcher, and J. L. Franklin, "Loss of cardiolipin and mitochondria during programmed neuronal death: evidence of a role for lipid peroxidation and autophagy," Neuroscience, vol. 115, no. 2, pp. 587-602, 2002.

[196] I. Kiššová, M. Deffieu, V. Samokhvalov et al., "Lipid oxidation and autophagy in yeast," Free Radical Biology and Medicine, vol. 41, no. 11, pp. 1655-1661, 2006.

[197] R. K. Dagda, S. J. Cherra, S. M. Kulich, A. Tandon, D. Park, and C. T. Chu, "Loss of PINK1 function promotes mitophagy through effects on oxidative stress and mitochondrial fission," Journal of Biological Chemistry, vol. 284, no. 20, pp. 13843-13855, 2009.

[198] D. C. Rubinsztein, M. DiFiglia, N. Heintz et al., "Autophagy and its possible roles in nervous system diseases, damage and repair," Autophagy, vol. 1, no. 1, pp. 11-22, 2005.

[199] J. H. Zhu, F. Guo, J. Shelburne, S. Watkins, and C. T. Chu, "Localization of phosphorylated ERK/MAP kinases to mitochondria and autophagosomes in lewy body diseases," Brain Pathology, vol. 13, no. 4, pp. 473-481, 2003.

[200] R. A. Nixon, J. Wegiel, A. Kumar et al., "Extensive involvement of autophagy in Alzheimer disease: an immunoelectron microscopy study," Journal of Neuropathology and Experimental Neurology, vol. 64, no. 2, pp. 113-122, 2005.

[201] S. J. Cherra and C. T. Chu, "Autophagy in neuroprotection and neurodegeneration: a question of balance," Future Neurology, vol. 3, no. 3, pp. 309-323, 2008.

[202] A. Martínez, M. Portero-Otin, R. Pamplona, and I. Ferrer, "Protein targets of oxidative damage in human neurodegenerative diseases with abnormal protein aggregates," Brain Pathology, vol. 20, no. 2, pp. 281-297, 2010.

[203] L. Zheng, K. Kågedal, N. Dehvari et al., "Oxidative stress induces macroautophagy of amyloid $\beta$-protein and ensuing apoptosis," Free Radical Biology and Medicine, vol. 46, no. 3, pp. 422-429, 2009. 
[204] P. I. Moreira, S. L. Siedlak, X. Wang et al., "Erratum: increased autophagic degradation of mitochondria in Alzheimer disease (Autophagy)," Autophagy, vol. 3, no. 6, pp. 614-615, 2007.

[205] B. Ravikumar, R. Duden, and D. C. Rubinsztein, "Aggregateprone proteins with polyglutamine and polyalanine expansions are degraded by autophagy," Human Molecular Genetics, vol. 11, no. 9, pp. 1107-1117, 2002.

[206] J. L. Webb, B. Ravikumar, J. Atkins, J. N. Skepper, and D. C. Rubinsztein, " $\alpha$-synuclein is degraded by both autophagy and the proteasome," Journal of Biological Chemistry, vol. 278, no. 27, pp. 25009-25013, 2003.

[207] J.-A. Lee and F.-B. Gao, "Regulation of A $\beta$ pathology by beclin 1: a protective role for autophagy?" Journal of Clinical Investigation, vol. 118, no. 6, pp. 2015-2018, 2008.

[208] B. Ravikumar, C. Vacher, Z. Berger et al., "Inhibition of mTOR induces autophagy and reduces toxicity of polyglutamine expansions in fly and mouse models of Huntington disease," Nature Genetics, vol. 36, no. 6, pp. 585-595, 2004.

[209] D. Narendra, A. Tanaka, D. F. Suen, and R. J. Youle, "Parkin is recruited selectively to impaired mitochondria and promotes their autophagy," Journal of Cell Biology, vol. 183, no. 5, pp. 795-803, 2008.

[210] O. Warburg, "On the origin of cancer cells," Science, vol. 123, no. 3191, pp. 309-314, 1956.

[211] D. C. Wallace, "Mitochondria and cancer: warburg addressed," Cold Spring Harbor Symposia on Quantitative Biology, vol. 70, pp. 363-374, 2005.

[212] M. Brandon, P. Baldi, and D. C. Wallace, "Mitochondrial mutations in cancer," Oncogene, vol. 25, no. 34, pp. 46474662, 2006.

[213] A. Chatterjee, E. Mambo, and D. Sidransky, "Mitochondrial DNA mutations in human cancer," Oncogene, vol. 25, no. 34, pp. 4663-4674, 2006.

[214] J. A. Petros, A. K. Baumann, E. Ruiz-Pesini et al., "MtDNA mutations increase tumorigenicity in prostate cancer," Proceedings of the National Academy of Sciences of the United States of America, vol. 102, no. 3, pp. 719-724, 2005.

[215] I. Trounce, S. Neill, and D. C. Wallace, "Cytoplasmic transfer of the mtDNA nt $8993 \mathrm{~T} \rightarrow \mathrm{G}$ (ATP6) point mutation associated with Leigh syndrome into mtDNA-less cells demonstrates cosegregation with a decrease in state III respiration and ADP/O ratio," Proceedings of the National Academy of Sciences of the United States of America, vol. 91, no. 18, pp. 8334-8338, 1994.

[216] Y. Li, T. T. Huang, E. J. Carlson et al., "Dilated cardiomyopathy and neonatal lethality in mutant mice lacking manganese superoxide dismutase," Nature Genetics, vol. 11, no. 4, pp. 376-381, 1995.

[217] S. Melov, P. Coskun, M. Patel et al., "Mitochondrial disease in superoxide dismutase 2 mutant mice," Proceedings of the National Academy of Sciences of the United States of America, vol. 96, no. 3, pp. 846-851, 1999.

[218] S. Melov, J. A. Schneider, B. J. Day et al., "A novel neurological phenotype in mice lacking mitochondrial manganese superoxide dismutase," Nature Genetics, vol. 18, no. 2, pp. 159-163, 1998.

[219] J. E. Kokoszka, P. Coskun, L. A. Esposito, and D. C. Wallace, "Increased mitochondrial oxidative stress in the Sod2 $(+/-)$ mouse results in the age-related decline of mitochondrial function culminating in increased apoptosis," Proceedings of the National Academy of Sciences of the United States of America, vol. 98, no. 5, pp. 2278-2283, 2001.
[220] Y. S. Ho, R. Vincent, M. S. Dey, J. W. Slot, and J. D. Crapo, "Transgenic models for the study of lung antioxidant defense: enhanced manganese-containing superoxide dismutase activity gives partial protection to b6c3 hybrid mice exposed to hyperoxia," American Journal of Respiratory Cell and Molecular Biology, vol. 18, no. 4, pp. 538-547, 1998.

[221] D. Hu, P. Cao, E. Thiels et al., "Hippocampal long-term potentiation, memory, and longevity in mice that overexpress mitochondrial superoxide dismutase," Neurobiology of Learning and Memory, vol. 87, no. 3, pp. 372-384, 2007.

[222] Y. C. Jang, V. I. Pérez, W. Song et al., "Overexpression of Mn superoxide dismutase does not increase life span in mice," Journals of Gerontology A, vol. 64, no. 11, pp. 1114-1125, 2009.

[223] I. Raineri, E. J. Carlson, R. Gacayan et al., "Strain-dependent high-level expression of a transgene for manganese superoxide dismutase is associated with growth retardation and decreased fertility," Free Radical Biology and Medicine, vol. 31, no. 8, pp. 1018-1030, 2001.

[224] B. H. Graham, K. G. Waymire, B. Cottrell, I. A. Trounce, G. R. MacGregor, and D. C. Wallace, "A mouse model for mitochondrial myopathy and cardiomyopathy resulting from a deficiency in the heart/muscle isoform of the adenine nucleotide translocator," Nature Genetics, vol. 16, no. 3, pp. 226-234, 1997.

[225] D. G. Murdock, B. E. Boone, L. A. Esposito, and D. C. Wallace, "Up-regulation of nuclear and mitochondrial genes in the skeletal muscle of mice lacking the heart/muscle isoform of the adenine nucleotide translocator," Journal of Biological Chemistry, vol. 274, no. 20, pp. 14429-14433, 1999.

[226] L. A. Esposito, S. Melov, A. Panov, B. A. Cottrell, and D. C. Wallace, "Mitochondrial disease in mouse results in increased oxidative stress," Proceedings of the National Academy of Sciences of the United States of America, vol. 96, no. 9, pp. 4820-4825, 1999.

[227] M. Behrens, G. Michaelis, and E. Pratje, "Mitochondrial inner membrane protease 1 of Saccharomyces cerevisiae shows sequence similarity to the Escherichia coli leader peptidase," Molecular and General Genetics, vol. 228, no. 1-2, pp. 167176, 1991.

[228] J. Nunnari, T. D. Fox, and P. Walter, "A mitochondrial protease with two catalytic subunits of nonoverlapping specificities," Science, vol. 262, no. 5142, pp. 1997-2004, 1993.

[229] M. D. Brand, "The sites and topology of mitochondrial superoxide production," Experimental Gerontology, vol. 45, no. 7-8, pp. 466-472, 2010.

[230] B. Lu, C. Poirier, T. Gaspar et al., "A mutation in the inner mitochondrial membrane peptidase 2-like gene (Immp2l) affects mitochondrial function and impairs fertility in mice," Biology of Reproduction, vol. 78, no. 4, pp. 601-610, 2008. 

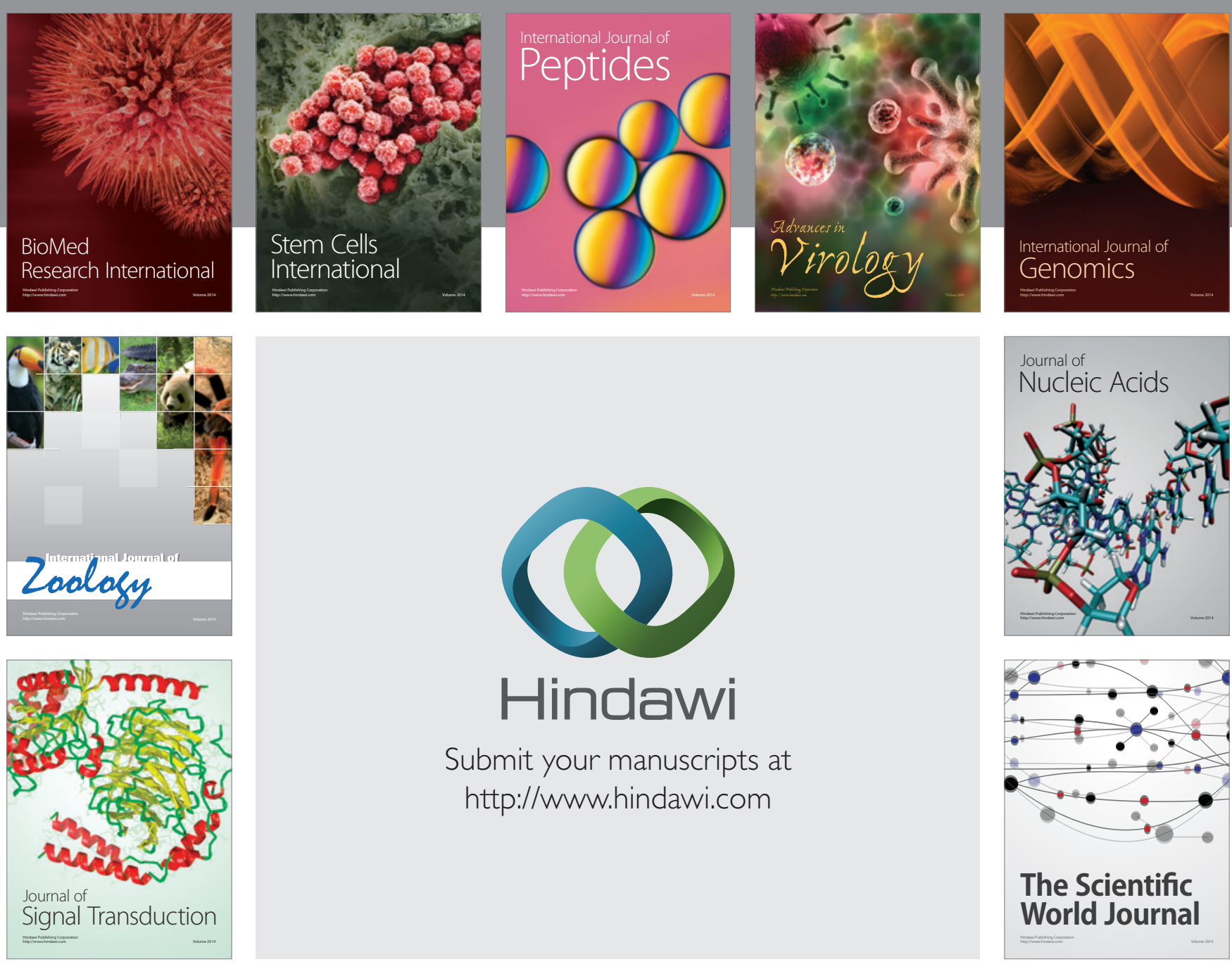

Submit your manuscripts at

http://www.hindawi.com
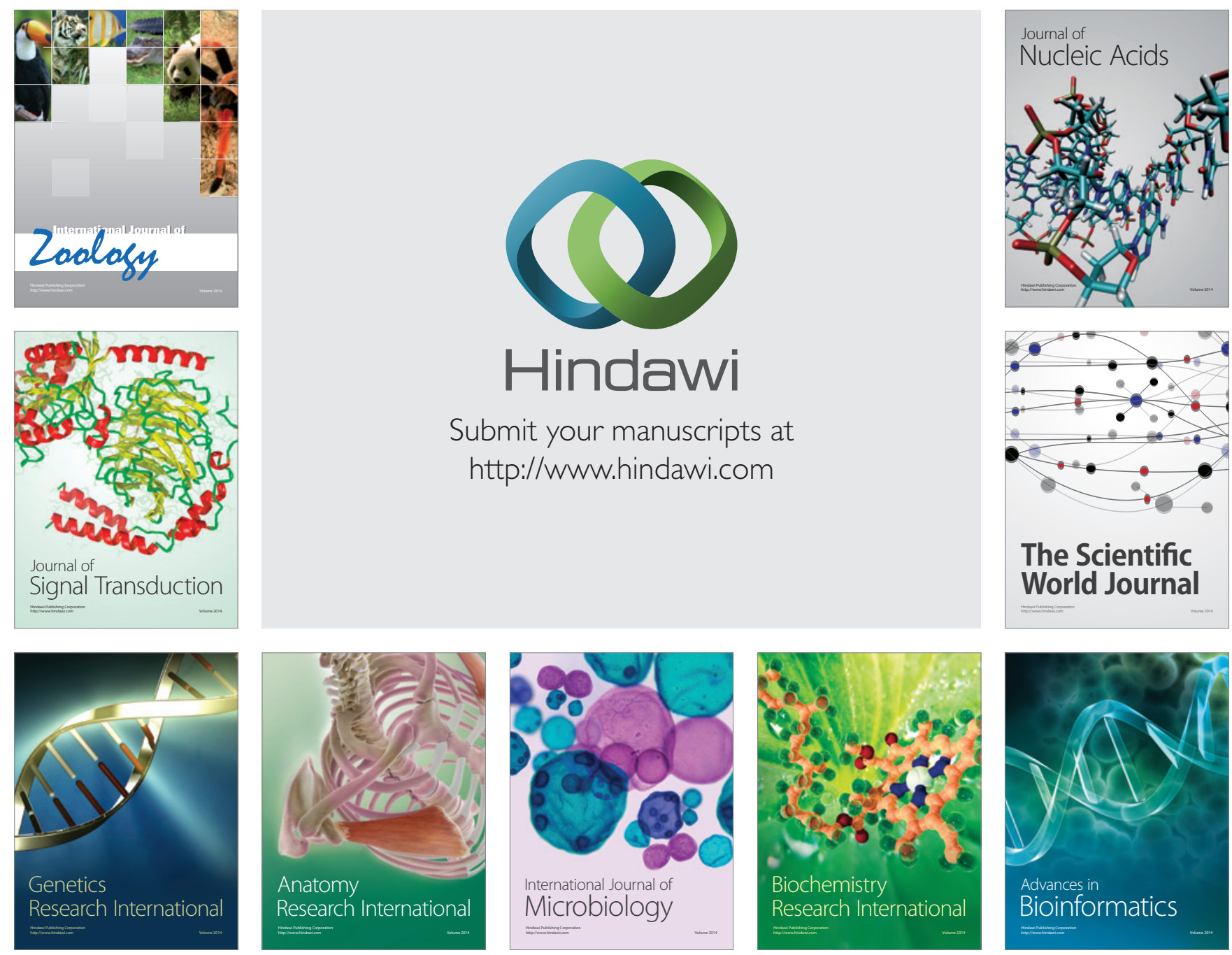

The Scientific World Journal
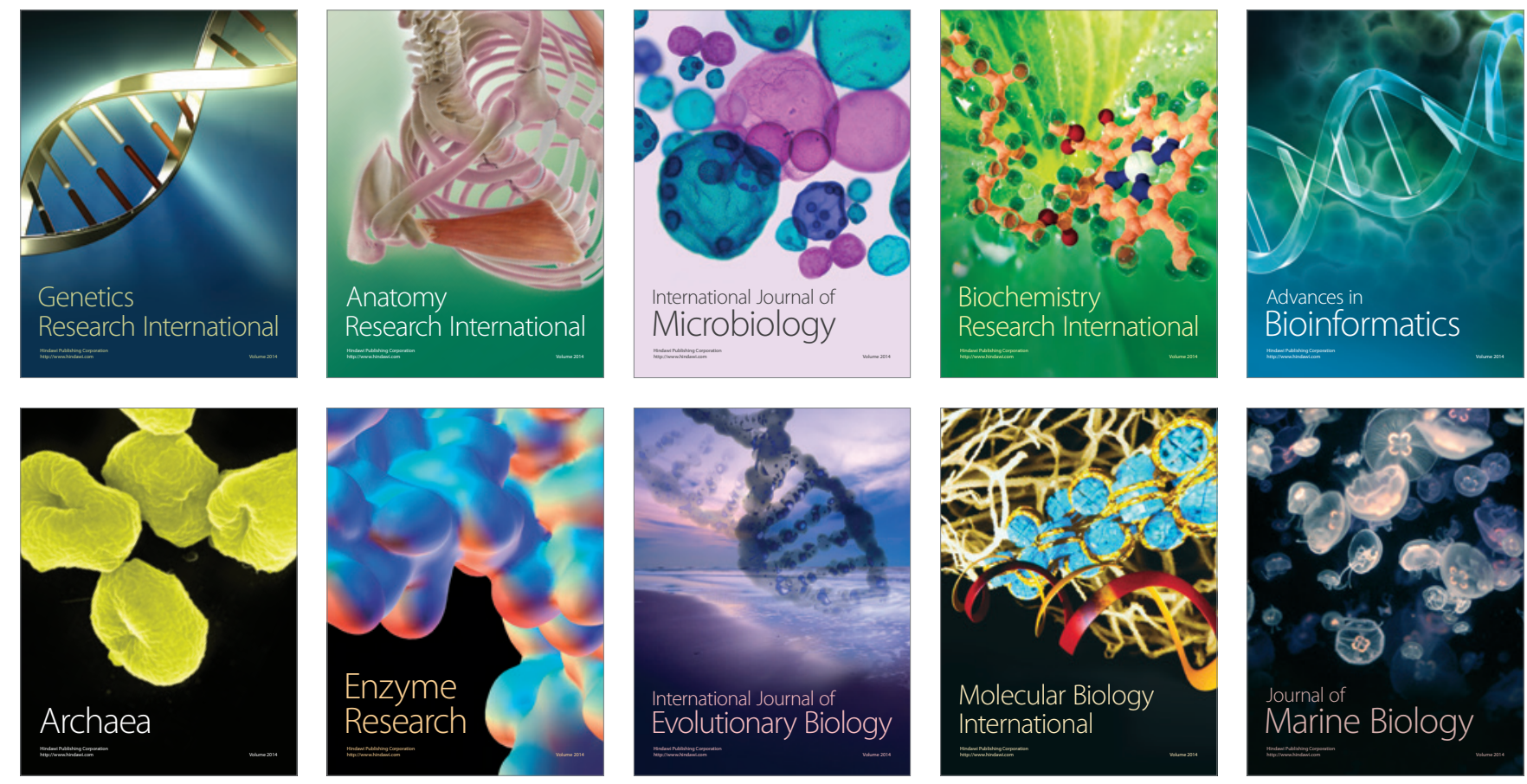